\title{
Simple Manoeuvre to Help Irrigate the Fascial Space Infections
}

\author{
P. V. Nimonkar
}

Received: 10 January 2012/ Accepted: 4 April 2012/Published online: 11 May 2012

(C) Association of Oral and Maxillofacial Surgeons of India 2012

Once incision and drainage of fascial space abscess is performed, drain is placed and the wound is dressed which is changed several times over subsequent days and irrigated daily. Irrigation with saline and antibiotic solution has been reported to be effective in the elimination or reduction of infection [1]. Irrigation is one of the distressing works after incision and drainage which demands the accessibility of irrigating solution in deeper areas. Nasogastric feeding tubes, French catheter or polyethylene irrigation tubes are few aids to meet this requirement [1]. However, they are not readily available in dental office. It is not uncommon for the irrigating tip of needle to move around in surgical field and frequently traumatize the adjacent tissue. Moreover, it was found that irrigating needles do not readily irrigate the inaccessible areas as it is tough to bend. To overcome these problems a simple method to irrigate such deep spaces is proposed here. Irrigation with scalp vein infusion set is easy, rapid and safe. Winged needle end of the infusion set is cut, 3-4 side holes can be created depending on the requirement of irrigation. The luer mount is of the size that can be fixed to the nozzle of the syringe containing irrigant (Fig. 1). Tube of infusion set is soft, made of polyethylene with adequate diameter and length to reach the inaccessible areas. This technique can enable easy, simple and safe irrigation of facial space particularly, those drained with corrugated drainage sheet. Closed wound irrigation can also be efficiently carried out with this technique. Hence, scalp vein infusion set is cheap and

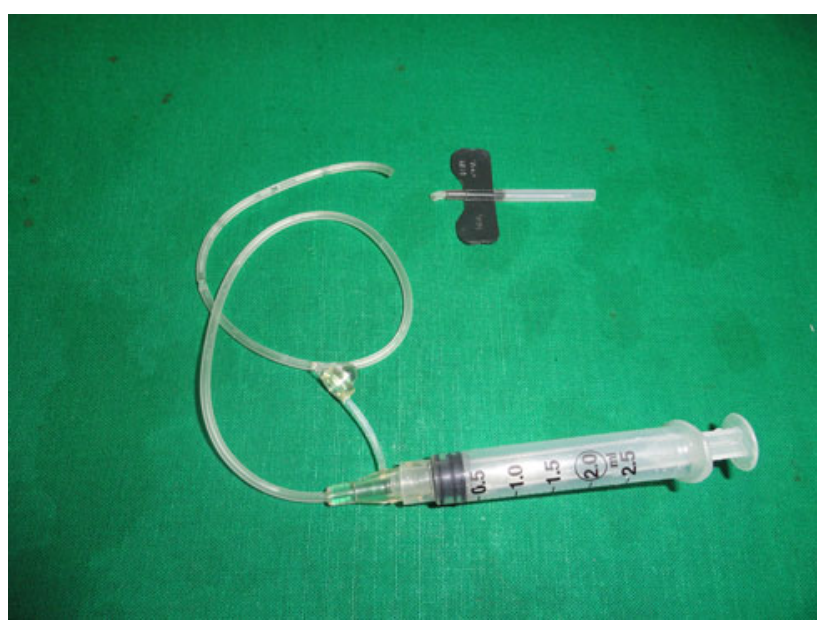

Fig. 1 Syringe attached to infusion set for irrigation

readily available, flexibility of which allows easy access without traumatizing the tissues.

\section{Reference}

1. Topazian RG (2002) Osteomyelitis of the Jaws. In: Topazian RG, Goldberg MH, Hupp JR (eds) Oral and Maxillofacial Infections, 4th edn. WB Saunders, Philadelphia, p 223 